\title{
http://revistainvestigacionacademicasinfrontera.com
}

Recibido el 28 de octubre de 2018. Dictaminado mediante arbitraje favorablemente 10 de diciembre de 2018

\section{El derecho constitucional y el actuar del criminólogo}

\section{Lic. Armando Medina Wahnnatah ${ }^{1}$ - Dra. María Guadalupe Almada Quintero² - Dr. Cirilo Duarte Félix ${ }^{3}$ - Ana Lucia Medina Almada ${ }^{4}$}

\begin{abstract}
Resumen
El presente expone brevemente el análisis de la relación que guarda el Marco Constitucional en México con la Criminología, respecto de la planeación de las actividades que realiza el sistema gubernamental y que de acuerdo a la estructura legal, se establece las facultades correlativas que tanto la Federación como las Entidades Federativas, tienen que realizar para lograr la planificación en pro de los habitantes.
\end{abstract}

Lo anterior, en relación con las generalidades de la criminología, ambas encaminadas a identificar las conductas de las personas cuando se relacionan con la comisión de los delitos,

Se enfoca este análisis desde sus aportes para la formación en profesionales de la criminología. Con un sentido social responsable para dirigir al estudio en su prevención, concibiendo al derecho y a las normas jurídicas como elementos para la reconstrucción social.

Palabras clave: Marco constitucional, criminología, prevención del delito, educación superior.

\footnotetext{
${ }^{1}$ Licenciado en Derecho por la Universidad de Sonora. Docente en la Universidad Estatal de Sonora. Campus Navojoa. licarmandomedinaw@hotmail.com

${ }^{2}$ Doctora en Planeación y Liderazgo Educativo por la Universidad del Valle de México. Campus Hermosillo. Docente en la Universidad Estatal de Sonora. magaq@hotmail.com

${ }^{3}$ Doctor en Investigación Educativa en la Instituto del Desierto de Santa Ana. Campus Navojoa. Docente en la Universidad Estatal de Sonora. duarte606@hotmail.com

${ }^{4}$ Estudiante en la Licenciatura en Derecho por la Universidad de Sonora, Unidad Regional Sur. Analuma00@hotmail.com
} 


\title{
http://revistainvestigacionacademicasinfrontera.com
}

\begin{abstract}
The present briefly exposes the analysis of the relationship that the Constitutional Framework in Mexico has with Criminology, with respect to the planning of the activities carried out by the governmental system and that, according to the legal structure, establishes the correlative faculties that both the Federation as the Federative Entities, they have to perform to achieve planning for the inhabitants.

The foregoing, in relation to the generalities of criminology, both aimed at identifying the behavior of people when they relate to the commission of crimes.

This analysis is focused on its contributions to the training of professionals in criminology. With a responsible social sense to direct the study in its prevention, conceiving the law and legal norms as elements for social reconstruction.
\end{abstract}

Keywords: Constitutional framework, criminology, crime prevention, higher education

\section{Introducción}

Este análisis se dirige a los elementos básicos en las materias del marco constitucional y de la criminología, ambos campos científicos y de gran relevancia dentro de la procuración, administración e impartición de la justicia, de igual forma en la investigación del delito y en la actuación del delincuente, lo cual hace indispensable un acercamiento al estudio, análisis y comprensión de la criminología y sus fundamentos legales.

Resulta evidente en épocas actuales la importancia de abordar desde el ámbito de la educación superior, en su contribución a la formación de los profesionales en el ámbito de la criminología, el tema del marco normativo que rige a los individuos en su forma particular 


\section{http://revistainvestigacionacademicasinfrontera.com}

y en las relaciones con los otros, para estar en posibilidades de promover acciones y estrategias para una buena y sana inserción de las personas en una sociedad como la que en día estamos viviendo, una sociedad cambiante, dinámica y en evolución constante, por lo cual se requiere de un análisis detallado del marco normativo que atienda a las necesidades más apremiantes de la colectividad con un sentido social responsable, que promueva desde la espera y ámbitos de la impartición de justicia los valores universales, el respeto a la dignidad humana y en el análisis de las penas y las sanciones se procure la comprensión del delincuente para la prevención de los conductas delictivas, como tarea principal de las instituciones de justicia.

\section{Método}

Atendiendo a Hernández, Sampieri (2010) En la presente investigación se emplea un enfoque dirigido al estudio cualitativo, se practica un análisis de contenido y se procede a la interpretación de la información, se emplea un diseño exploratorio por medio del cual se obtiene información detallada resaltando los aspectos teóricos y doctrinarios como apoyo en el estado de arte. En la interpretación del Marco Constitucional Mexicano como base para la ciencia criminológica en el estudio de la comisión de los delitos, dirigiendo el análisis hacia la contribución de la educación superior en la formación de profesionales en la ciencia criminológica con la responsabilidad social de la inserción del individuo en la sociedad.

\section{Resultados}

No obstante la Criminología es una ciencia autónoma, se halla íntimamente relacionada con todas aquellas que estudian el delito y tienen por fin último luchar contra él. Es imposible pensar en una ciencia única del delito. Si eso ocurrió en algún momento pasado, hoy es una imposibilidad teórica y práctica. Ha surgido una especialización creciente. Pero si ésta ha 


\section{http://revistainvestigacionacademicasinfrontera.com}

traído beneficios claros, como la mayor profundidad de la investigación y la discriminación de los métodos que deben emplearse, es también evidente que hay el peligro como en toda especialización, de sólo estudiar y concebir el delito desde un ángulo, olvidando o tomando a menos los demás.

De la especialización exagerada resultan deformaciones, posiciones unilaterales que más perjudican que impulsan el avance de la ciencia. Al tratar de la historia de la Criminología, veremos cuánto tiempo se ha perdido, cuántos errores se cometieron al encarar todo el problema delictivo sólo desde el punto de vista hereditario, endocrino, psiquiátrico, económico, etc.

Es importante precisar que la Criminología guarda estrecha relación de interdependencia con otras ramas del saber, sobre las que influye, por lo que cada disciplina representa un papel en el todo (Hikal. 2011).

En México la Constitución Política es el principio de todo ordenamiento, y por lo mismo es necesario tomarla como la base en todo estudio jurídico, es innegable que en nuestro sistema jurídico nos encontramos supeditados a los mandamientos expresados en nuestra Carta Magna. La Constitución es, en consecuencia, el marco normativo en que las instituciones encuentran su fundamento y sus límites; el lugar en que estas convergen a fin de esbozar los mecanismos de actuación y control que permitan el adecuado funcionamiento del estado.

La Constitución de 1917, es un compendio vivo de nuestra historia y la suma de todo aquello por lo que los mexicanos hemos trabajado, luchado y creído. En 1917 el pueblo mexicano, después de más de un siglo de conflictos, fincó el carácter de sus instituciones y aclaró el destino político del país, creando una forma republicana de gobierno, que el ejercicio del poder se realizara a partir de una clara y efectiva división de poderes, que el contrapeso real a la concentración de poder se efectuara a través de un sistema federal; que los ciudadanos gozáramos de garantías individuales y que disfrutáramos de las sociales. Un Estado laico que respetara todo tipo de creencias religiosas, en la vigencia de la libertad de conciencia y 


\section{http://revistainvestigacionacademicasinfrontera.com}

de expresión y en el derecho inalienable de participar en la formación de las decisiones del Gobierno (Serrano. 2017).

En este mismo sentido, y citando a Peñaloza (2004). El estado debe tutelar de la sociedad en el marco del "Estado de derecho" con una justicia penal democrática por medio de la tarea preventiva sin dejar de lado la función persecutoria, pero contribuyendo a una visión integral de las problemáticas para aportar de igual forma soluciones integrales apostando a que son las verdaderamente eficaces y duraderas. Es importante señalar que el enfoque constitucionalista del Derecho penal es el fundamento de la pena y del Derecho penal. Tanto las sanciones penales como la elección de la conducta a sancionar debe tratarse de decisiones

fundamentadas directamente en algunas de las características del ilícito o de la sanción penal, de acuerdo a las propias condiciones o requisitos que establezca la respectiva norma constitucional en materia penal

Como señala Gutiérrez (2015) La Constitución política cumple determinadas funciones en el ámbito del sistema penal, entre otras, la de influir directamente en la práctica jurídica a través de los supuestos concretos que se presentan ante los Tribunales de justicia. Ello, principalmente, porque los Tribunales deben tener presente lo dispuesto en la Constitución para los efectos de aplicarlo directamente o de interpretar, de acuerdo con la misma, los preceptos ordinarios que requieran de una adecuación hermenéutica respecto del texto constitucional, de forma tal que toda contradicción entre éstos y la Constitución democrática debe resolverse a favor de esta última.

De igual forma, la Constitución cumpliría una función de orientación de la concreta políticapenal a desarrollar por el Estado. Esto es, que la Constitución, dentro de su propio marco político-criminal general y de sus valores y principios, puede establecer o promocionar determinadas sanciones y figuras penales que deben tenerse en cuenta por el legislador en el futuro. 


\section{http://revistainvestigacionacademicasinfrontera.com}

La Constitución tendría una importante función doctrinal pues permite la elaboración de teorías en relación con la interpretación de la ley, la teoría del delito, el bien jurídico, la teoría de la pena o la propia reforma del sistema penal.

Por otra parte y en relación al marco constitucional y la criminología, es importante señalar que si se pretende luchar contra el delito, hay que conocer sus causas para poder evitar las consecuencias papel fundamental que desempeña la criminología, como la ciencia encargada de investigar el delito y al delincuente a través de sus métodos por lo que la aplicación de la ley de forma equiparada es la función del estado.

Es importante la tarea del estado y de la propia criminología como ciencia al incidir en la prevención delictiva es tarea fundamental organizar centros penitenciarios que tengan como finalidad la corrección, educación, hábitos de trabajo a delincuentes y como función fundamental el procurar su readaptación para el logro de la prevención de los delitos.

\section{Conclusiones}

El contexto de la globalización y la modernización en general provocan cambios y procesos evolutivos en muchos de los rubros importantes en los que se desenvuelve diariamente el individuo. En este escenario es fundamental adecuar los procesos de enseñanza-aprendizaje, fortaleciendo la educación continua.

Es primordial entender el proceso formativo como un proceso de transmisión de conocimientos, cultura y valores, es claro que se verá sometida a nuevas exigencias, lo cual implica un importante escenario para la convivencia en una sociedad plural, tolerante y democrática.

Por otra parte, esta globalización también tiene fuerte impacto en el análisis del marco normativo, entendiendo su implicación en todo el quehacer cotidiano de los individuos. En este sentido enfocamos el análisis del marco constitucional con el actuar diario del criminólogo desde su profesionalización al ser la Constitución la norma suprema de nuestro 


\section{http://revistainvestigacionacademicasinfrontera.com}

ordenamiento es fundamental conocer su contenido y desarrollo, resulta de gran relevancia acercarse al marco normativo para su adecuado ejercicio.

Es prioritario en el marco de la educación superior, y sobre todo en la profesionalización de la licenciatura en Criminología, aproximarse al estudio del análisis del Estado, sus elementos y formas de organización, conocer el ámbito constitucional-legal en que se desenvuelve en su quehacer el profesional de la ciencia criminológica, reconociendo el hecho de que se encuentra ligada al estudio de las ciencias jurídicas.

El derecho constitucional está integrado entre otros elementos por preceptos constitucionales sobre mandatos, prohibiciones y regulaciones, incluyendo entre ellos la consagración expresa de un fin de la pena que, junto con la prevención del delito, en el modelo de Estado social y democrático esta generalmente constituido por el principio de la reinserción social, en el marco de una sistema constitucional democrático encaminado a la prevención de la comisión de los delitos.

Es importante destacar, en este mismo sentido le necesidad de una mejora continua en los procesos de la formación jurídica integral, resaltar además los valores éticos y sociales presentes en nuestros ordenamientos legales a través de normas positivas o los principios generales del derecho y de una cultura jurídica en general 


\section{http://revistainvestigacionacademicasinfrontera.com}

Referencias

Gutiérrez. A.L. (2015). El estado de derecho y la política criminal en México.

http://www.pensamientopenal.com.ar/system/files/2015/11/doctrina42320.pdf

Hernández. S. (2010). Metodología de la investigación. 5ta. Ed. McGRAW-HILL /

Interamericana Editores, S.A. DE C.V.

Hikal. W. (2011). La ciencia criminológica.

https://www.revistaciencia.amc.edu.mx/images/revista/62_2/PDF/07_Criminologica.pdf

Serrano.F.M. (2017). La constitución mexicana y el marco institucional.

http://www.revistacomercioexterior.com/articulo.php?id=279\&t=la-constitucion-

mexicana-y-el-marco-institucional.

Peñaloza, P. J., La prevención del delito: una asignatura pendiente. México, Porrúa, 2004, 199 pp. http://www.scielo.org.mx/scielo.php?script=sci_arttext\&pid=S0041$\underline{86332005000100013}$

\section{Como citar este articulo}

Armando Medina Wahnnatah-María Guadalupe Almada Quintero-Cirilo Duarte FélixAna Lucia Medina Almada. El derecho constitucional y el actuar del criminólogo. RIASF. Núm. 28, Julio-diciembre (2018), ISSN 2007-8870. pp. xx-xx. 